\title{
Self-Reflection and the Inner Voice: Activation of the Left Inferior Frontal Gyrus During Perceptual and Conceptual Self-Referential Thinking
}

\author{
Alain Morin ${ }^{*}$ and Breanne Hamper
}

Department of Psychology, Mount Royal University, 4825 Richard Road S.W., Calgary, Alberta, Canada T3E 6 K6

\begin{abstract}
Inner speech involvement in self-reflection was examined by reviewing 130 studies assessing brain activation during self-referential processing in key self-domains: agency, self-recognition, emotions, personality traits, autobiographical memory, and miscellaneous (e.g., prospection, judgments). The left inferior frontal gyrus (LIFG) has been shown to be reliably recruited during inner speech production. The percentage of studies reporting LIFG activity for each self-dimension was calculated. Fifty five percent of all studies reviewed indicated LIFG (and presumably inner speech) activity during self-reflection tasks; on average LIFG activation is observed $16 \%$ of the time during completion of non-self tasks (e.g., attention, perception). The highest LIFG activation rate was observed during retrieval of autobiographical information. The LIFG was significantly more recruited during conceptual tasks (e.g., prospection, traits) than during perceptual tasks (agency and self-recognition). This constitutes additional evidence supporting the idea of a participation of inner speech in self-related thinking.
\end{abstract}

Keywords: Self-awareness, self-reflection, self-referential activity, inner speech, self-talk, verbal labeling, left inferior frontal gyrus, language, conceptual self-domains, perceptual self-domains, brain-imaging.

\section{INTRODUCTION}

Self-referential activity is currently the target of numerous brain-imaging studies aimed at determining what brain areas get reliably activated during self-reflection tasks. The consensus is that the following regions underlie self-related processing: cortical medial structures, which include ventromedial and dorsomedial prefrontal cortex, lateral prefrontal cortex, precuneus, insula, temporoparietal junction, and anterior/posterior cingulate cortex [for reviews, see 1-6].

Ruby and Legrand [7] recently proposed that memory recall and inferential reasoning constitute particular computational ingredients recruited when one is engaged in self-referential processing. That is, most self-reflection tasks employed in brain-imaging studies require one form or another of memory and evaluation involving a certain degree of uncertainty (e.g., does this personality trait apply to me?). Consistent with this hypothesis, most aforementioned brain areas recruited during self-reflection are also activated during memory recall and inferential reasoning.

Another elementary process potentially recruited during self-reflection is the inner voice [8-12]. Verbalizing one's characteristics to oneself or engaging in a complex silent verbal self-analysis is postulated to facilitate the identification, storage, and retrieval of self-information [for details see 13]. Inner speech is known to serve various important cognitive functions [for reviews see 14-16], among which are planning [17], self-regulation [18], selfcontrol [19], and memory [20], including working memory [21]. The idea that one often "thinks" (including about oneself) in words is certainly not new (Plato, cited in [22]);

*Address correspondence to this author at the Department of Psychology, Mount Royal University, 4825 Richard Road S.W., Calgary, Alberta, Canada T3E 6K6; Tel: 403-440-7069; E-mail: amorin@mtroyal.ca what is novel is empirical evidence establishing connections between self-reflection and the inner voice. To illustrate, people report talking to themselves mostly about themselves [23]. Various validated frequency measures of self-focus and self-talk significantly correlate [e.g., 24, 25]. Deterioration of inner speech following a left lateralized stroke is associated with self-awareness deficits [10].

Morin and Michaud [26] noted that inner speech production consistently recruits the left inferior frontal gyrus (LIFG) and reported a relatively high incidence of LIFG activation during self-reflection tasks, suggesting inner speech activity during at least some self-information processing. More specifically, this team reviewed 59 brainimaging studies of self-awareness in the following selfdomains: agency, self-recognition, emotions, personality traits, autobiographical memory, and preference judgments. Resting state (REST) studies were also included because of the introspective quality of that state [20]. Fifty-six percent of all studies reviewed identified LIFG and presumably inner speech activity during self-reflection tasks. In addition, the LIFG was more frequently recruited during conceptual selftasks (e.g., emotions, traits) than during perceptual self-tasks (agency and self-recognition). This possibly suggests that more abstract self-aspects need to be verbalized in order to be fully brought to consciousness.

The main goal of the present meta-analysis was to expand Morin and Michaud's original results [26] by combining them with a new set of brain-imaging studies of self-reflection published since 2006 . The overall principle here [reverse inference; see 27] is that researchers can infer what particular thought processes are solicited during a given social cognitive task by concentrating on peripheral structures instead of on a core network. For example, retrieval of autobiographical information often activates 
occipital regions [28]; control tasks typically do not lead to such an activation. Since these areas are known to support visuospatial imagery [29], one may suggest that retrieval of autobiographical memories is at least partially mediated by mental images of the self in the past [30]. Similarly, activation of the LIFG observed in Morin and Michaud's review [26] has been taken as an indication that participants engaged in inner speech during various self-tasks.

The LIFG represents the neurological foundation of both overt and covert speech generation. The LIFG is also referred to as the left ventrolateral prefrontal cortex or left frontal operculum; it includes Broadmann's areas 44, 45, and 47. There is little doubt that the LIFG is implicated in inner speech production. Numerous studies show LIFG activation when participants are asked to silently read single words or sentences, or when undertaking working memory tasks involving covert repetition of verbal material [e.g., 31-33]. Moreover, accidental destruction or temporary disruption (using repetitive transcranial magnetic stimulation) of the LIFG interferes with inner speech [34-36]. Note that other brain areas are associated with inner voice use, among which Wernicke's area, the supplementary motor area, insula, and superior parietal lobe on the left side, as well as right posterior cerebellar cortex [for a review see 37].

It has been proposed that the LIFG serves additional functions besides covert speech per se, including cognitive control [38], working memory [39], language unification [40], selection among competing alternatives [41, 42], response inhibition [43], and action understanding [44]. It is conceivable that most, if not all, listed functions above actually require subvocal articulation. For instance, articulatory suppression (i.e., blocking inner speech) negatively affects performance on cognitive control and verbal working memory tasks $[45,46]$. Hence the observation of an activation of the LIFG during both inner speech production and tasks designed to test the aforementioned functions. In other words, one could argue that LIFG activation most often signifies inner speech use, be it for cognitive control or working memory purposes, or for any other possible reasons, including self-reflection. Given this, and considering the fact that self-tasks presented in the next section most unlikely involve cognitive control, working memory, language unification, selection among competing alternatives, response inhibition, and action understanding, LIFG activity in this review was interpreted as indirect evidence of inner speech use by participants.

The first objective of the present meta-analysis was to determine if LIFG activation is observed in a significant number of brain-imaging studies of self-reflection. Different ways of classifying self-dimensions exist [see 2, 3]. In this paper self-tasks were put into the following self-domains: agency, self-recognition, emotions, personality traits, autobiographical memory, and miscellaneous. This latter category included experiments imaging participants thinking about their intentions, hopes, aspirations, mental states, preferences, as well as self-evaluation and prospection tasks (i.e., thoughts about one's future).

A second aim was to compare LIFG activation in perceptual (agency and self-recognition) and conceptual (e.g., autobiography, traits) self-domains, where inner speech use is hypothesized to be more important in the latter. Perceptual (sensory) self-information refers to products of one's direct experience with oneself (e.g., the body) or environmental stimuli (e.g., other persons, mirrors) that identify the self. Conceptual self-information constitutes data about the self that is not available to immediate perceptual experience and that presumably requires mental representation to be accessible to consciousness. This division between perceptual and conceptual self-domains echoes the distinction between physical and psychological selves proposed by Gillihan and Farah [2, 47]. Perceptual self-information such as one's face during self-recognition, because of its visual and concrete nature, most probably does not need to be verbally labeled (e.g., "this is my face") to successfully complete the task. Agency tasks typically involve evaluating the degree of one's participation in a given action and thus mostly rely on kinesthetic information. Reflection on more abstract self-dimensions such as past memories and intentions however, possibly entail subvocal speech (e.g., "I spent last summer at my brother's place"; "I want to go swimming") to be fully brought to one's attention.

\section{METHOD}

English-language papers published between September 2006 and August 2010 were identified from searches using Medline, Psycarticle, and Psycinfo, as well as the Psychology and Behavioral Sciences Collection. ${ }^{1}$ The reference section of each article was scrutinized for additional studies. Review articles were also carefully examined. Inclusion criteria for selection of articles were all studies measuring brain activity using hemodynamic methods (Positron Emission Tomography [PET] and functional magnetic resonance imaging [fMRI]) during selfrelated tasks pertaining to the aforementioned self-domains. Exclusion criteria were: (a) articles using Theory-of-Mind (ToM) tasks, as opposed to purely self-referential tasks [e.g., 48]; (b) electrophysiological studies using event-related potentials, as well as those employing EEG and Transcranial Magnetic Stimulation [e.g., 49]; (c) studies imaging clinical populations exclusively [e.g. 50]; and (d) studies not reporting all areas of activation and uniquely focusing on regions of interest [e.g., 51]. ToM and self-reflection abilities are linked in complex ways [see 52] and common brain areas are recruited when one both introspects and thinks about others' mental states [53]. Nonetheless, ToM abilities fundamentally differ from self-reflection abilities in that the former focuses on other social agents whereas the latter exclusively pertains to the self [54]. This is why we excluded ToM studies from the present meta-analysis.

The application of this selection process led to the identification of 68 articles; we added to these articles 59 previously identified by Morin and Michaud [26] in the same self-domains. These authors used the same search and selection processes describe above for articles published

\footnotetext{
'Keywords were searched in the title of articles. Keywords used were: agency, autobiographical, autobiography, autonetic, brain, cortical, emotion awareness, emotion recognition, fMRI, future thoughts, intentions, introspection, judgments, mental time travel, neural correlates, neural substrates, neuroanatomy, personality traits, PET, preferences, self, self-awareness, self-face, self-processing, self-projection, self-recognition, self-referential, and self-reflection.
} 


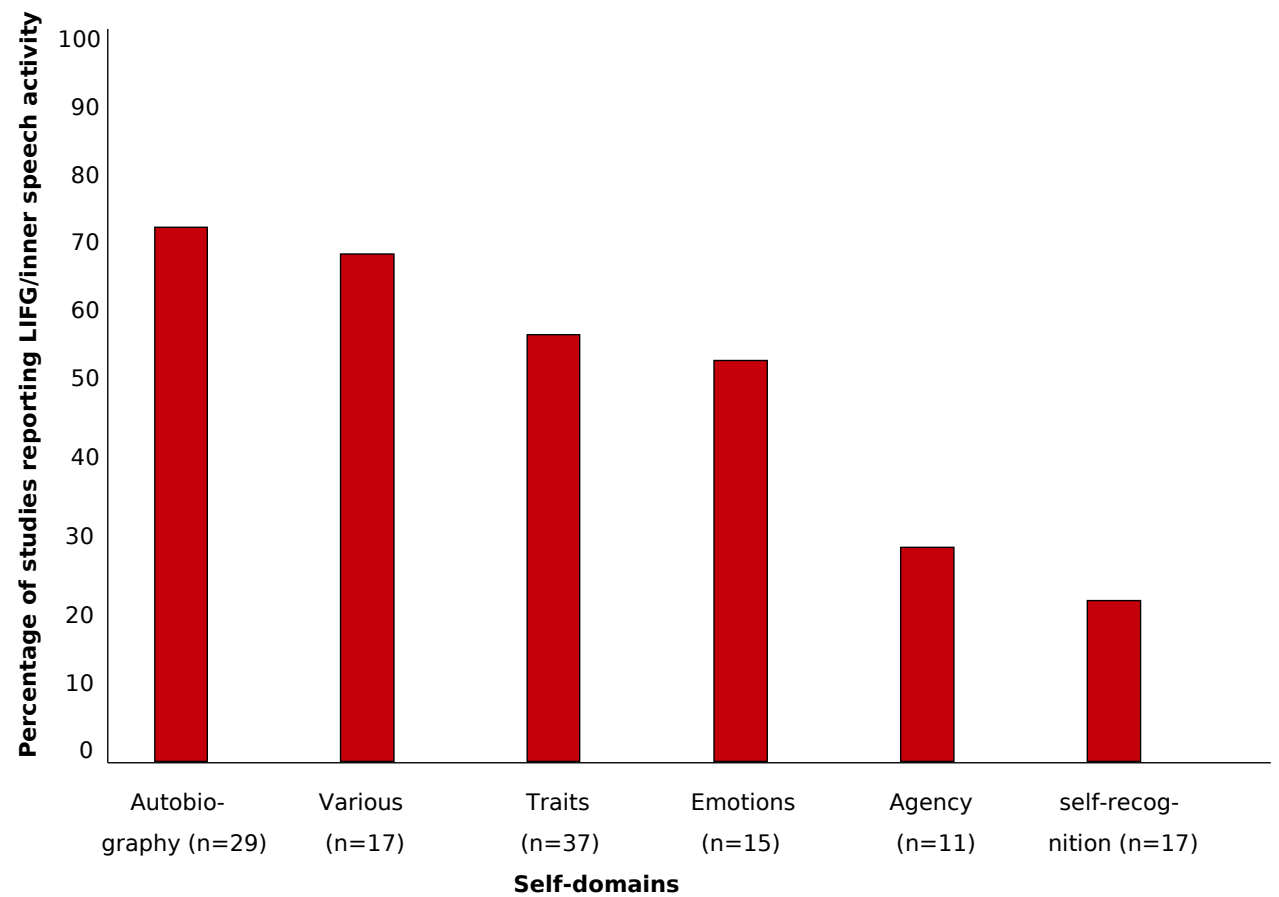

Fig. (1). Percentage of studies in which LIFG activity was observed as a function of self-domains.

Table 1. LIFG Activation Observed in Various Non-Self Domains (Based on 26). Language and Working Memory Domains are not Reported

\begin{tabular}{|l|c|c|c|}
\hline \multicolumn{1}{|c|}{ Domain } & N of Studies Reviewed & $\begin{array}{c}\text { N of Studies Reporting } \\
\text { LIFG Activation (BA 44/45/47) }\end{array}$ & $\begin{array}{c}\text { Percentage of LIFG } \\
\text { Activation }\end{array}$ \\
\hline \hline Attention & 39 & 3 & 7.7 \\
\hline Perception & 42 & 8 & 19 \\
\hline Imagery & 18 & 3 & 29.4 \\
\hline Non-verbal episodic memory encoding & 17 & 5 & 16.7 \\
\hline Non-verbal episodic memory retrieval & 70 & 10 & 37.5 \\
\hline Priming & 16 & 6 & 3.7 \\
\hline Procedural memory & 27 & 1 & 15.7 \\
\hline ALL & 229 & 36 & \\
\hline
\end{tabular}

prior to September 2006. In all, we thus examined 127 articles containing 130 individual studies (some papers contained more than one study). Frequency of LIFG activation reported in these articles is presented in the Results section. Note that we uniquely concentrated on LIFG recruitment during self-conditions and deliberately ignored control conditions because inner speech participation during these control conditions is likely. To illustrate, inner speech use most likely will be recruited during a control task consisting in judging how socially desirable personality traits are, as in Craig et al. [55]. As mentioned earlier, inner speech serves various purposes in addition to the processing of self-information; control tasks such as encoding semantic information or making decisions about statements of factual knowledge often recruit subvocal speech. Thus we are not making the claim that inner speech use is special to the self; indeed, recent reviews rather suggest that there is actually little special about or unique to the self $[2,7]$. However, we hypothesize that the inner voice represents a privileged cognitive tool the self uses when assessing itself.

\section{RESULTS AND DISCUSSION}

\subsection{Overview}

Fig. (1) depicts the percentage of studies in which LIFG activity was observed in all selected self-domains. Seventy two of all 130 studies $(55.3 \%)$ indicated activation of the LIFG during self-awareness tasks. Percentages for each selfdomain were: 76.9 for autobiography, 56.7 for traits, 53.3 for emotions, 27.3 for agency, and 23.5 for self-recognition. The "miscellaneous" self-domain $(66.7 \%)$ included studies using evaluative judgment tasks involving the assessment of one's own preferences in order to produce a judgment, REST studies, as well as future-oriented thinking studies.

We submit that $55 \%$ represents a significant percentage, especially when compared to LIFG activation percentages that have been observed during various non-self tasks. Cabeza and Nyberg [29] reviewed studies of brain activations in various non-self cognitive domains such as attention and procedural memory. We excluded language 
Table 2. Agency studies. $(P)=$ Employed PET

\begin{tabular}{|c|c|c|}
\hline Paper & Self-task & LIFG Activation \\
\hline Farrer \& Frith [58] (P) & Driving circle along T-shaped path either by oneself or experimenter & NO \\
\hline Farrer et al. [59] (P) & Providing accurate/inaccurate visual feedback while performing hand movements & NO \\
\hline Knoblich et al. [60] & Deciding temporal delay between hand movements \& visual feedback & NO \\
\hline Leube et al. [61] & See [59] & NO \\
\hline McGuire et al. [62] (P) & Providing accurate/inaccurate auditory feedback while reading aloud & NO \\
\hline Powell et al. [63] & Choosing one of 4 deck cards presented on a screen & NO \\
\hline Ruby \& Decety [64] (P) & Imagining self vs other movements & NO \\
\hline Salomon et al. [56] & Deciding if hand movements are self- or other- generated & NO \\
\hline Vinogradov et al. [65] & Judging if words were preselected by self or experimenter & YES \\
\hline Wraga et al. [66] & Imagining rotating one's body & YES \\
\hline Yomogida et al. [67] & Controlling character's movements/actions with joystick & YES \\
\hline
\end{tabular}

and working memory studies, and observed that only $16 \%$ of 213 studies report LIFG activity (see Table 1). Again, in this perspective an activation of the LIFG in 55\% of all selfreferential thinking studies reviewed appears significant.

Given the nature of self-tasks reviewed here (see below for descriptions), this LIFG activity most probably reflects inner speech use instead of other possible LIFG functions such as response inhibition or action understanding. These results thus tentatively support the view that the inner voice substantially participates in at least some forms of selfreferential processing.

Consistent with the idea of a greater inner speech involvement in conceptual self-domains, we found that $63.7 \%$ of all conceptual studies $(\mathrm{n}=102$; autobiography, miscellaneous, emotions, and traits) reported activation of the LIFG, as opposed to $25 \%$ of all perceptual studies $(n=28)$ of agency and face/voice self-recognition. This difference is statistically significant, $\chi 2(1)=-3.770, p=.005$. This supports the view of a differential involvement of inner speech across self-domains, where perceptual self-dimensions (e.g., one's face) can be consciously perceived without words, whereas conceptual self-aspects (e.g., autobiography; prospection) most probably demand verbalization.

\subsection{Agency and Self-Recognition}

All Tables included below detail (1) the authors of individual articles, (2) self-tasks used, and (3) the presence or absence of LIFG activation. Note that unless otherwise indicated all studies used fMRI imaging technology. Table 2 presents 11 reviewed articles in the agency self-domain. A typical agency study [e.g., 56] invites participants to decide if they are responsible for the movement of their hand [for a review see 57]. Three of the agency studies out of 11 $(27.3 \%)$ reported LIFG activation.

Table 3 shows 17 reviewed articles in the selfrecognition domain. Most self-face recognition studies [e.g., 68 ] involve participants judging if a face seen on a screen is their own or that of another person [for reviews see 69, 70]. Four self-recognition studies out of 17 (23.5\%) reported LIFG activation. Sugiura et al.'s observation [71] that “(...) covert naming often accompanies recognition of a familiar face, but rarely occurs during visual self-recognition" (p. 147 ) is consistent with the notion that self-face recognition unlikely necessitates verbal labeling. Indeed, multiple brain networks for visual self-recognition have been identified [see 72], none of which include the LIFG).

\subsection{Personality Traits}

Most early self-reflection studies consisted in asking participants to determine if adjective traits were selfdescriptive [e.g., 55, 88]. This represents a simple, straightforward, and yet effective way of inducing self-focus, as one's personality certainly constitutes a central aspect of the self. Twenty one out of 37 personality trait studies (56.7\%) reported LIFG activation (see Table 4). Current neuropsychological and brain-imaging evidence suggests that once personality traits have been inferred by reflecting on specific and repeated behavioral instances, their retrieval becomes rather automatic and does not require autobiographical recollection [89]. This could explain why 16 of the reviewed studies did not find brain activity suggestive of verbal processing. It remains unclear why some studies did report the target activation while others did not despite using identical experimental tasks.

\subsection{Autobiographical Memory}

Remembering past personal events represents a fundamental human mental activity connected in complex ways to autonoetic consciousness and the self [123-125]. Thinking about one's past and imagining one's future (prospection; see next section) seem to depend on common underlying regions, notably the medial prefrontal cortex and lateral temporal corticles [126]. In a representative study of autobiographical memory [e.g., 127], some of the participants' past personal events are collected prior to scanning and each event gets associated with a verbal or visual cue; cues are then presented during scanning and volunteers are asked to recall the associated events in details. Table 5 shows that 20 of the 26 studies analyzed $(76.9 \%$ ) reported LIFG activation. This constitutes the highest activation rate of all self-domains. Although introspection suggests that we often replay past personal episodes in "pictures", some studies indicate that we also use inner speech when developing self-narratives [128-130]. Indeed, a left ventrolateral activation which includes the LIFG is often observed in autobiographical remembering [28, 131]. 
Table 3. Self-recognition Studies. $(P)=$ Employed PET

\begin{tabular}{|c|c|c|}
\hline Paper & Self-task & LIFG Activation \\
\hline Devue et al. [73] & Judging if face is self or other & YES \\
\hline Kaplan et al. [74] & See [73] & NO \\
\hline Kircher et al. [75] & See [75] & YES \\
\hline Kircher et al. [76] & See [73] & YES \\
\hline Morita et al. [77] & See [73] & NO \\
\hline Perrin et al. $[78](\mathrm{P})$ & Listening to one's, unfamiliar, \& common names & NO \\
\hline Platek et al. [79] & See [73] & NO \\
\hline Platek et al. [80] & See [73] & NO \\
\hline Platek \& Kemp [81] & See [73] & NO \\
\hline Sachdev et al. [82] & Judging if face $\&$ body shape are self or other & NO \\
\hline Sugiura et al. $[83](\mathrm{P})$ & See [73] & NO \\
\hline Sugiura et al. [71] & See [73] & NO \\
\hline Sugiura et al. [84] & Judging if face \& voice are self or other & YES \\
\hline Sugiura et al. [68] & See [73] & NO \\
\hline Sui \& Han [85] & See [73] & NO \\
\hline Uddin et al. [86] & Deciding if faces are composites of oneself or other & NO \\
\hline Uddin et al. [87] & Viewing full body images of self & NO \\
\hline
\end{tabular}

Table 4. Personality Trait Studies. $(P)=$ Employed PET

\begin{tabular}{|c|c|c|}
\hline Paper & Self-task & LIFG Activation \\
\hline Blackwood et al. [90] & Judging if various traits, activities \& emotions are self-descriptive & NO \\
\hline Chiao et al. [91] & Judging self-descriptiveness of sentences & NO \\
\hline Craik et al. $[55]$ (P) & Judging if adjective traits are self-descriptive & YES \\
\hline D'Argembeau et al. [92] & See [55] & YES \\
\hline D'Argembeau et al. [93] & See [55] & NO \\
\hline Farb et al. [94] & See [55] & YES \\
\hline Fossati et al. [95] & See [55] & NO \\
\hline Gutchess et al. [96] & See [55] & YES \\
\hline Han et al. [97] & See [55] & YES \\
\hline Heatherton et al. [98] & See [55] & YES \\
\hline Jenkins \& Mitchell [99] & See [55] & NO \\
\hline Kelley et al. [100] & See [55] & YES \\
\hline Kircher et al. [75] & Judging if adjective traits \& physical characteristics are self-descriptive & YES \\
\hline Kjaer et al. $[101](\mathrm{P})$ & Silently thinking about one's traits \& physical appearance & $\begin{array}{c}\text { YES } \\
\text { (physical appearance only) }\end{array}$ \\
\hline Lemogne, le Bastard, Mayberg, et al. [102] & See [55] & NO \\
\hline Lemogne, Mayberg, Bergouignan, et al. [103] & See [55] & YES \\
\hline Lieberman et al. [104] & See [55] & YES \\
\hline Lou et al. [105] (P) & See [55] & YES \\
\hline Macrae et al. [106] & See [55] & YES \\
\hline Modinos et al. [107] & Judging self-descriptiveness of sentences about personal qualities & NO \\
\hline Moran et al. [108] & See [55] & NO \\
\hline Moran et al. [109] & See [55] & YES \\
\hline $\mathrm{Ng}$ et al. [110] & See [55] & YES \\
\hline Ochsner et al. [111] & See [55] & YES \\
\hline
\end{tabular}


Table 4. contd....

\begin{tabular}{|c|c|c|}
\hline Pfeifer et al. [112] & See [91] & YES \\
\hline Powell et al. [63] & See [55] & YES \\
\hline Rameson et al. [113] & See [55] & NO \\
\hline Ries et al. [114] (P) & See [55] & NO \\
\hline Schmitz et al. [115] & See [55] & NO \\
\hline Schmitz et al. [116] & See [55] & NO \\
\hline Vanderwal et al. [117] & See [55] & YES \\
\hline Wu et al. [118] & See [55] & NO \\
\hline Yaoi et al. [119] & See [55] & YES \\
\hline Yoshimura et al. [120] & See [55] & NO \\
\hline Zhang et al. [121] & See [55] & NO \\
\hline Zhu et al. [122] & See [55] & YES \\
\hline
\end{tabular}

Table 5. Autobiographical Memory Studies. $(P)=$ Employed PET

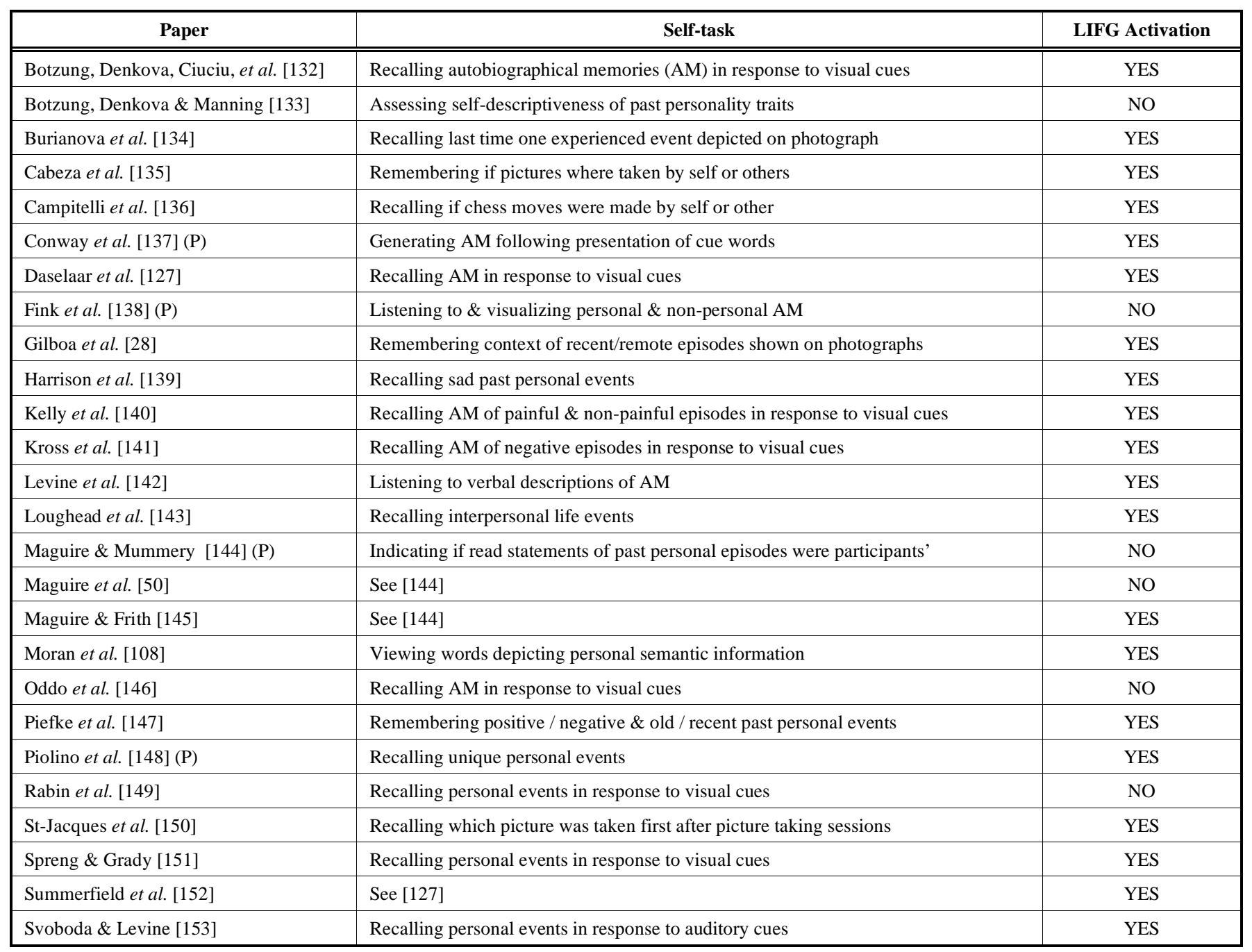

\subsection{Emotions}

The notion that verbal labeling of emotions enhances emotion awareness is not new [see 154]. It seems plausible to suggest that verbally identifying one's feelings through inner speech (e.g., "I feel tired and irritated... actually, I feel angry and disappointed...") helps distinguishing between subtle emotional experiences [13]. Reappraisal represents a cognitive emotion regulation strategy which consists in rethinking the meaning of affectively charged stimuli or events to decrease their emotional impact. Interestingly, brain-imaging studies of reappraisal consistently show recruitment of ventral portions of the PFC involved in language functions [155]. As shown in Table 6, 8 out of 15 emotion studies $(53.3 \%)$ reported LIFG activity. 
Table 6. Emotion Studies. $(P)=$ Employed PET

\begin{tabular}{|c|c|c|}
\hline Paper & Self-task & LIFG activation \\
\hline Critchley et al. [156] & Perceiving (or not) feedback delay of one's heartbeat (interoception) & YES \\
\hline Goldberg et al. [157] & Evaluating emotional experiences produced by images \& music & YES \\
\hline Gusnard et al. [158] & Evaluating one's emotional responses to visual cues & YES \\
\hline Herwig et al. [159] & See $[158]$ & YES \\
\hline Jackson et al. [160] & Imagining levels of pain by viewing normal \& distorted limbs & YES \\
\hline Lane et al. $[161](\mathrm{P})$ & See $[158]$ & YES \\
\hline Northoff et al. [5] & Evaluating degree of self-relatedness to visual cues & NO \\
\hline Ochsner et al. [162] & See $[158]$ & YES \\
\hline Phan et al. [163] & Indicating emotional association with pictures & NO \\
\hline Schneider et al. [164] & See [5] & NO \\
\hline Sheline et al. [165] & Reflecting on current emotional experiences & NO \\
\hline Silani et al. [166] & See $[158]$ & NO \\
\hline Takahashi et al. [167] & Judging if guilt \& embarrassment are present in short sentences & $\begin{array}{c}\text { YES } \\
\text { (embarrassment } \\
\text { only) }\end{array}$ \\
\hline Takahashi et al. [168] & Imagining joyful or proud scenarios in response to visual cues & NO \\
\hline Taylor et al. [169] (P) & Rating aversive \& nonaversive pictures & NO \\
\hline
\end{tabular}

Table 7. Various self-referential Studies. $(P)=$ Employed PET

\begin{tabular}{|c|c|c|}
\hline Paper & Self-task & LIFG Activation \\
\hline Addis et al. [175] & Pre-experiencing future personal events in response to visual cues & YES \\
\hline Arzy et al. [176] & Indicating if personal events occurred before/after currently imagined self-location in time & YES \\
\hline Binder et al. [177] & Resting still with eyes closed & YES \\
\hline Blackemore et al. [170] & Thinking about intentions \& consequential actions in response to presentation of fictive scenarios & NO \\
\hline Botzung et al. [133] & See $[175]$ & NO \\
\hline Christoff et al. [178] & See $[177]$ & YES \\
\hline D'Argembeau et al. [93] & Pre-experiencing future personal events in response to visual cues & NO \\
\hline D'Argembeau et al. [179] & See [93] & YES \\
\hline Fransson [180] & See $[177]$ & YES \\
\hline Jenkins \& Mitchell [99] & Judging one's current mental state in response to visual cues & YES \\
\hline Johnson et al. [181] & Choosing which color one prefers & YES \\
\hline Johnson et al. [182] & Thinking about hopes $\&$ aspirations in response to visual cues & YES \\
\hline Longe et al. [183] & Imagining being self-reassuring/self-critical after negative fictive scenarios & YES \\
\hline Mazoyer et al. $[184](\mathrm{P})$ & See $[177]$ & YES \\
\hline Pan et al. [185] & Presenting positive, negative $\&$ neutral evaluative feedback through visual cues & NO \\
\hline Paulus \& Frank [186] & Determine which one of two items one prefers & NO \\
\hline Pfeifer et al. [187] & Making direct/reflected self-appraisals in response to visual cues & YES \\
\hline Piech et al. [188] & Judging if one likes or dislikes food & NO \\
\hline Seger et al. [189] & See $[188]$ & NO \\
\hline Spreng \& Grady [155] & See $[93]$ & YES \\
\hline Szpunar et al. [190] & See [175] & NO \\
\hline Weiler et al. [191] & See [175] & YES \\
\hline Zysset et al. [192] & Making evaluative judgments of people & YES \\
\hline
\end{tabular}




\subsection{Miscellaneous}

Table 7 shows that 16 out of 24 miscellaneous studies $(66.7 \%)$ reported LIFG activation. Studies in this general category included various forms of self-focus such as intentions, hopes, aspirations, mental states, preferences, self-evaluation, and self-location in time. To illustrate, one study invited volunteers to reflect on their intentions in response to the presentation of fictive scenarios [170]. Also included were studies of mental projections of the self into the future ("mental time travel", "episodic future thinking", "future-oriented cognition", "foresight") [for reviews see $126,171,172]$. People report producing both mental images and inner speech when engaging in prospection [173]. The role of language in prospection is increasingly being discussed in the literature [e.g., 124, 174]. Our review of brain-imaging studies of prospection is consistent with these ideas. A typical prospection study invites participants to imagine a future personal event in response to the presentation of a visual cue, e.g., a word ("camping") or a photograph of a tent to stimulate thoughts about a possible future camping trip [see 151]. Phenomenologically speaking, one can propose that such tasks may trigger an internal dialogue such as "I can smell the odor of the tent... It will be fun to wake up early with the sun... Fishing in the creek nearby too will be fun..."

\section{CONCLUSION}

One major difference between human and non-human animals is that the former possess language and the ability to engage in self-talk [193]. This ability to verbally communicate with the self in turn is assumed to lead to increased cognitive complexity which includes deeper selfreferential processing [194]. This paper presented evidence suggesting that inner speech is often used by participants working on various self-reflection tasks. The data show that speech-for-self when thinking about the self is significant, as $55 \%$ as all studies reviewed reported LIFG activation, as opposed to $16 \%$ in non-self tasks [29]. This conclusion is acceptable only if one embraces the underlying assumption that LIFG activation indicates inner speech use; this assumption is currently supported by neuropsychological and brain-imaging research. Our results also imply a differential involvement of inner speech across self-domains, where reflection on conceptual self-dimensions seems to rely more on verbalization than reflection on perceptual self-aspects. Sixty four percent of studies pertaining to abstract selfdomains such as autobiographical memory and personality traits reported LIFG activation, as opposed to $25 \%$ of studies of a more perceptual nature.

One limitation of the approach used here is that it remains possible that the activation of the LIFG observed in some studies may reflect other cognitive mechanisms in addition to, or instead of, inner speech use. Although it is possible that LIFG activation underlies semantic processing during some tasks (e.g., personality traits), it is unlikely that the self-tasks described in the Tables require cognitive control, working memory, language unification, selection among competing alternatives, response inhibition, and action understanding.
One hotly debated issue in the literature is the importance of language (and by extension, of inner speech) for ToM [see 195]. Both ToM and most self-reflection tasks involve making inferences about psychological attributes of people-either self or others. Since inner speech seems to play a role in thinking about oneself, it could also constitute the mental activity underlying thinking about others. Indeed, recent work indicates that ToM development is linked to private speech use in preschoolers [196]; also, children with autism (a condition associated with ToM deficits) underuse inner speech [17]. A large quantity of published brainimaging studies of ToM exists [for a review see 197]. One promising strategy to further test the hypothesis of inner speech involvement in ToM could consist in calculating the percentage of reported LIFG activation across mental state domains e.g., false belief, deceit, intentions, empathy, desires, and pretence.

\section{CONFLICT OF INTEREST}

The authors confirm that this article content has no conflicts of interest.

\section{ACKNOWLEDGEMENTS}

We would like to thank Jessica Bertson, Meghan MacKenzie, Angela Bladon, Bob Uttl, and Petra Kamstra for their help with statistical calculations, article analysis, and/or editing commentaries on this manuscript.

\section{REFERENCES}

[1] Feinberg TE. The nested neural hierarchy and the self. Conscious Cogn 2011; 20(1): 4-15.

[2] Gillihan SJ, Farah MJ. Is self special? a critical review of evidence from experimental psychology and cognitive neuroscience. Psychol Bull 2005; 131(1): 76-97.

[3] Northoff G, Heinzel A, de Greck M, Bermpohl F, Dobrowolny H, Panksepp J. Self-referential processing in our brain--a metaanalysis of imaging studies on the self. Neuroimage 2006; 15; 31(1): 440-57.

[4] Northoff G, Qin P, Feinberg TE. Brain imaging of the self-conceptual, anatomical and methodological issues. Conscious Cogn 2011; 20(1): 52-63.

[5] Northoff G, Schneider F, Rotte M, et al. Differential parametric modulation of self-relatedness and emotions in different brain regions. Hum Brain Mapp 2009; 30(2): 369-82.

[6] van der Meer L, Costafreda S, Aleman A, David AS. Selfreflection and the brain: a theoretical review and meta-analysis of neuroimaging studies with implications for schizophrenia. Neurosci Biobehav Rev 2010; 34(6): 935-46.

[7] Legrand D, Ruby P. What is self-specific? Theoretical investigation and critical review of neuroimaging results. Psychol Rev 2009; 116(1): 252-82.

[8] DeSouza M, DaSilveira A, Gomes W. Verbalized inner speech and the expressiveness of self-Consciousness. Qual Res Psychol 2008; 5(2): 154-70.

[9] Martínez-Manrique F, Vicente A. "What the...!" The role of inner speech in conscious thought. J Conscious Stud 2010; 17(9-10): 141-67.

[10] Morin A. Self-awareness deficits following loss of inner speech: Dr. Jill Bolte Taylor's case study. Conscious Cogn 2009; 18(2): 524-9.

[11] Neuman Y, Nave O. Why the brain needs language in order to be self-conscious. New Ideas Psychol 2010; 28(1): 37-48.

[12] Werning M. Descartes discarded? Introspective self-awareness and the problems of transparency and compositionality. Conscious Cogn 2010; 19(3): 751-61.

[13] Morin A. Possible links between self-awareness and inner speech: Theoretical background, underlying mechanisms, and empirical evidence. J Conscious Stud 2005; 12(4-5): 115-34. 
[14] Morin A. Inner speech. Encyclopedia of human behavior. $2^{\text {nd }}$ ed. W. Hirstein, Ed. UK: Elsevier 2011.

[15] Hubbard TL. Auditory imagery: empirical findings. Psychol Bull 2010; 136(2): 302-29.

[16] Vicente A, Martinez Manrique F. Inner speech: Nature and functions. Philos Compass 2011; 6(3): 209-19.

[17] Lidstone JSM, Fernyhough C, Meins E, Whitehouse AJO. Brief report: Inner speech impairment in children with autism is associated with greater nonverbal than verbal skills. J Autism Dev Disord 2009; 39(8): 1222-5.

[18] Vygotsky L. Thought and Language. Cambridge, MA: MIT Press 1934.

[19] Tullett AM, Inzlicht M. The voice of self-control: blocking the inner voice increases impulsive responding. Acta Psychol (Amst) 2010; 135(2): 252-6.

[20] Buckner RL, Andrews-Hanna JR, Schacter DL. The brain's default network: anatomy, function, and relevance to disease. Ann NY Acad Sci 2008; 1124: 1-38.

[21] Marvel CL, Desmond JE. From storage to manipulation: How the neural correlates of verbal working memory reflect varying demands on inner speech. Brain Lang 2012; 120(1): 42-51.

[22] Blachowicz J. The dialogue of the soul with itself. in Models of the Self. Gallagher S, Shear J, Eds. Exeter UK: Imprint Academic 1999; pp. 177-200.

[23] Morin A, Uttl B, Hamper B. Self-reported frequency, content, and functions of inner speech. Procedia Soc Behav Sci 2011; 30: 17148.

[24] Schneider JF, Pospeschill M, Ranger J. Does self-consciousness mediate the relation between self-talk and self-knowledge? Psychol Rep 2005; 96(2): 387-96.

[25] Siegrist M. Inner speech as a cognitive process mediating selfconsciousness and inhibiting self-deception. Psychol Rep 1995; 76(1): 259-65.

[26] Morin A, Michaud J. Self-awareness and the left inferior frontal gyrus: Inner speech use during self-related processing. Brain Res Bull 2007; 74(6): 387-96.

[27] Poldrack RA. Can cognitive processes be inferred from neuroimaging data? Trends Cogn Sci 2006; 10(2): 59-63.

[28] Gilboa A, Winocur G, Grady CL, Hevenor SJ, Moscovitch M. Remembering our past: functional neuroanatomy of recollection of recent and very remote personal events. Cereb Cortex 2004; 14(11): 1214-25.

[29] Cabeza R, Nyberg L. Imaging cognition II: an empirical review of 275 PET and fMRI studies. J Cogn Neurosci 2000; 12(1): 1-47.

[30] Svoboda E, McKinnon MC, Levine B. The functional neuroanatomy of autobiographical memory: a meta-analysis. Neuropsychologia 2006; 44(12): 2189-208.

[31] Baciu MV, Rubin C, Décorps MA, Segebarth CM. fMRI assessment of hemispheric language dominance using a simple inner speech paradigm. NMR Biomed 1999; 12(5): 293-8.

[32] McGuire PK, Silbersweig DA, Murray RM, David AS, Frackowiak RS, Frith CD. Functional anatomy of inner speech and auditory verbal imagery. Psychol Med 1996; 26(1): 29-38.

[33] McGuire PK, Silbersweig DA, Wright I, Murray RM, Frackowiak RS, Frith CD. The neural correlates of inner speech and auditory verbal imagery in schizophrenia: relationship to auditory verbal hallucinations. Br J Psychiatr 1996; 169(2): 148 -59.

[34] Aziz-Zadeh L, Cattaneo L, Rochat M, Rizzolatti G. Covert speech arrest induced by rTMS over both motor and nonmotor left hemisphere frontal sites. J Cogn Neurosci 2005; 17(6): 928-38.

[35] Nixon P, Lazarova J, Hodinott-Hill I, Gough P, Passingham R. The inferior frontal gyrus and phonological processing: an investigation using rTMS. J Cognitive Neurosci 2004; 16(2): 289-300.

[36] Verstichel P, Bourak C, Font V, Crochet G. Langage intérieur après lésion cérébrale gauche: Étude de la représentation phonologique des mots chez des patients aphasiques et non aphasiques. Neuropsychology J 1997; 7(3): 281-311.

[37] Jones SR, Fernyhough C. Neural correlates of inner speech and auditory verbal hallucinations: a critical review and theoretical integration. Clin Psychol Rev 2007; 27(2): 140-54.

[38] Brass M, Derrfuss J, Forstmann B, von Cramon DY. The role of the inferior frontal junction area in cognitive control. Trends Cogn Sci 2005; 9(7): 314-6.

[39] Paulesu E, Frith CD, Frackowiak RS. The neural correlates of the verbal component of working memory. Nature 1993; 362(6418): $342-5$.
[40] Hagoort P. On Broca, brain, and binding: a new framework. Trends Cogn Sci 2005; 9(9): 416-23.

[41] Kan IP, Thompson-Schill SL. Effect of name agreement on prefrontal activity during overt and covert picture naming. Cogn Affect Behav Neurosci 2004; 4(1): 43-57.

[42] Thompson-Schill SL, D'Esposito M, Aguirre GK, Farah MJ. Role of left inferior prefrontal cortex in retrieval of semantic knowledge: a reevaluation. Proc Natl Acad Sci USA 1997; 94(26): 14792-7.

[43] Swick D, Ashley V, Turken AU. Left inferior frontal gyrus is critical for response inhibition. BMC Neurosci 2008; 9: 102.

[44] Baumgaertner A, Buccino G, Lange R, McNamara A, Binkofski F. Polymodal conceptual processing of human biological actions in the left inferior frontal lobe. Eur J Neurosci 2007; 25(3): 881-9.

[45] Cragg L, Nation K. Language and the development of cognitive control. Top Cogn Sci 2010; 2(4): 631-42.

[46] Morris N, Jones DM. Memory updating in working memory: the role of the central executive. Br J Psychol 1990; 81(2):111-21.

[47] Williams D. Theory of own mind in autism: Evidence of a specific deficit in self-awareness? Autism 2010; 14(5): 474-94.

[48] Moriguchi Y, Ohnishi T, Lane RD, et al. Impaired self-awareness and theory of mind: an fMRI study of mentalizing in alexithymia. Neuroimage 2006; 32(3): 1472-82.

[49] Heinisch C, Dinse HR, Tegenthoff M, Juckel G, Brüne M. An rTMS study into self-face recognition using video-morphing technique. Soc Cogn Affect Neurosci 2011; 6(4): 442-9.

[50] Maguire EA, Kumaran D, Hassabis D, Kopelman MD. Autobiographical memory in semantic dementia: A longitudinal fmri study. Neuropsychologia 2010; 48(1): 123-36.

[51] Jenkins AC, Macrae CN, Mitchell JP. Repetition suppression of ventromedial prefrontal activity during judgments of self and others. Proc Natl Acad Sci USA 2008; 105(11): 4507-12.

[52] Dimaggio G, Lysaker PH, Carcione A, Nicolò G, Semerari A. Know yourself and you shall know the other to a certain extent: multiple paths of influence of self-reflection on mindreading. Conscious Cogn 2008; 17(3): 778-89.

[53] Rameson LT, Lieberman MD. Empathy: a social cognitive neuroscience approach. Soc Person Psychol Compass 2009; 3(1): 94-110.

[54] Morin A. Self-awareness and the left hemisphere: the dark side of selectively reviewing the literature. Cortex 2007; 43(8): 1068-1073; discussion 1074-1082.

[55] Craik FIM, Moroz TM, Moscovitch M, et al. In search of the self: A positron emission tomography study. Psychol Sci 1999; 10(1): 26-34.

[56] Salomon R, Malach R, Lamy D. Involvement of the intrinsic/default system in movement-related self recognition. PLoS One 2009; 4(10): e7527.

[57] Synofzik M, Vosgerau G, Newen A. I move, therefore I am: a new theoretical framework to investigate agency and ownership. Conscious Cogn 2008; 17(2): 411-24.

[58] Farrer C, Frith CD. Experiencing oneself vs another person as being the cause of an action: the neural correlates of the experience of agency. Neuroimage 2002; 15(3): 596-603.

[59] Farrer C, Franck N, Georgieff N, Frith CD, Decety J, Jeannerod M Modulating the experience of agency: a positron emission tomography study. Neuroimage 2003; 18(2): 324-33.

[60] Knoblich G, Leube D, Erb M, Kircher TTJ. Brain networks for identifying one's own actions. Poster presented at 13th Conference of the European Society for Cogn Psychology (ESCoP XIII), Granada, Spain 2003.

[61] Leube DT, Knoblich G, Erb M, Grodd W, Bartels M, Kircher TTJ. The neural correlates of perceiving one's own movements. Neuroimage 2003; 20(4): 2084-90.

[62] McGuire PK, Silbersweig DA, Wright I, Murray RM, Frackowiak RS, Frith CD. The neural correlates of inner speech and auditory verbal imagery in schizophrenia: relationship to auditory verbal hallucinations. Br J Psychiatry 1996; 169(2): 148-59.

[63] Powell LJ, Macrae CN, Cloutier J, Metcalfe J, Mitchell JP. Dissociable Neural Substrates for Agentic versus Conceptual Representations of Self. J Cogn Neurosci 2010; 22(10): 2186-97.

[64] Ruby P, Decety J. Effect of subjective perspective taking during simulation of action: a PET investigation of agency. Nat Neurosci 2001; 4(5): 546-50.

[65] Vinogradov S, Luks TL, Simpson GV, Schulman BJ, Glenn S, Wong AE. Brain activation patterns during memory of cognitive agency. Neuroimage 2006; 31(2): 896-905. 
[66] Wraga M, Shephard JM, Church JA, Inati S, Kosslyn SM. Imagined rotations of self versus objects: an fMRI study. Neuropsychologia 2005; 43(9): 1351-61.

[67] Yomogida Y, Sugiura M, Sassa Y, et al. The neural basis of agency: an fMRI study. Neuroimage 2010; 50(1): 198-207.

[68] Sugiura M, Sassa Y, Jeong H, Horie K, Sato S, Kawashima R. Face-specific and domain-general characteristics of cortical responses during self-recognition. Neuroimage 2008; 42(1): 41422.

[69] Devue C, Brédart S. The neural correlates of visual selfrecognition. Conscious Cogn 2011; 20(1): 40-51.

[70] Platek SM, Wathne K, Tierney NG, Thomson JW. Neural correlates of self-face recognition: an effect-location meta-analysis. Brain Res 2008; 1232: 173-84.

[71] Sugiura M, Watanabe J, Maeda Y, Matsue Y, Fukuda H, Kawashima R. Cortical mechanisms of visual self-recognition. Neuroimage 2005; 24(1): 143-9.

[72] Sugiura M. Cortical networks for visual self-recognition. Plasma Fusion Res 2007; 2: S1005.

[73] Devue C, Collette F, Balteau E, et al. Here I am: the cortical correlates of visual self-recognition. Brain Res 2007; 1143: 169-82.

[74] Kaplan JT, Aziz-Zadeh L, Uddin LQ, Iacoboni M. The self across the senses: an fMRI study of self-face and self-voice recognition. Soc Cogn Affect Neurosci 2008; 3(3): 218-23.

[75] Kircher TT, Senior C, Phillips ML, et al. Towards a functional neuroanatomy of self processing: effects of faces and words. Brain Res Cogn Brain Res 2000; 10(1-2): 133-44.

[76] Kircher TT, Senior C, Phillips ML, et al. Recognizing one's own face. Cognition 2001; 78(1): B1-B15.

[77] Morita T, Itakura S, Saito DN, et al. The role of the right prefrontal cortex in self-evaluation of the face: a functional magnetic resonance imaging study. J Cogn Neurosci 2008; 20(2): 342-55.

[78] Perrin F, Maquet P, Peigneux P, et al. Neural mechanisms involved in the detection of our first name: a combined ERPs and PET study. Neuropsychologia 2005; 43(1): 12-9.

[79] Platek SM, Keenan JP, Gallup GG Jr, Mohamed FB. Where am I? The neurological correlates of self and other. Brain Res Cogn Brain Res 2004; 19(2): 114-22.

[80] Platek SM, Loughead JW, Gur RC, et al. Neural substrates for functionally discriminating self-face from personally familiar faces. Hum Brain Mapp 2006; 27(2): 91-8.

[81] Platek SM, Kemp SM. Is family special to the brain? An eventrelated fMRI study of familiar, familial, and self-face recognition. Neuropsychologia 2009; 47(3): 849-58.

[82] Sachdev P, Mondraty N, Wen W, Gulliford K. Brains of anorexia nervosa patients process self-images differently from non-selfimages: an fMRI study. Neuropsychologia 2008; 46(8): 2161-8.

[83] Sugiura M, Kawashima R, Nakamura K, et al. Passive and active recognition of one's own face. Neuroimage 2000; 11(1): 36-48.

[84] Sugiura M, Sassa Y, Jeong H, et al. Multiple brain networks for visual self-recognition with different sensitivity for motion and body part. Neuroimage 2006; 32(4): 1905-17.

[85] Sui J, Han S. Self-construal priming modulates neural substrates of self-awareness. Psychol Sci 2007; 18(10): 861-6.

[86] Uddin LQ, Kaplan JT, Molnar-Szakacs I, Zaidel E, Iacoboni M. Self-face recognition activates a frontoparietal "mirror" network in the right hemisphere: an event-related fMRI study. Neuroimage 2005; 25(3): 926-35.

[87] Uddin LQ, Davies MS, Scott AA, et al. Neural basis of self and other representation in autism: an FMRI study of self-face recognition. PLoS One 2008; 3(10): e3526.

[88] Johnson SC, Baxter LC, Wilder LS, Pipe JG, Heiserman JE, Prigatano GP. Neural correlates of self-reflection. Brain J Neurol 2002; 125(8): 1808-14.

[89] Klein SB, Rozendal K, Cosmides L. A social-cognitive neuroscience analysis of the self. Soc Cogn 2002; 20(2): 105-35.

[90] Blackwood NJ, Bentall RP, Ffytche DH, Simmons A, Murray RM, Howard RJ. Persecutory delusions and the determination of selfrelevance: an fMRI investigation. Psychol Med 2004; 34(4): 591-6.

[91] Chiao JY, Harada T, Komeda H, et al. Neural basis of individualistic and collectivistic views of self. Hum Brain Mapp 2009; 30(9): 2813-20.

[92] D'Argembeau A, Feyers D, Majerus S, et al. Self-reflection across time: cortical midline structures differentiate between present and past selves. Soc Cogn Affect Neurosci 2008; 3(3): 244-52.
[93] D'Argembeau A, Stawarczyk D, Majerus S, et al. The neural basis of personal goal processing when envisioning future events. J Cogn Neurosci 2010; 22(8): 1701-13.

[94] Farb NAS, Segal ZV, Mayberg H, et al. Attending to the present: mindfulness meditation reveals distinct neural modes of selfreference. Soc Cogn Affect Neurosci 2007; 2(4): 313-22.

[95] Fossati P, Hevenor SJ, Graham SJ, et al. In search of the emotional self: an fMRI study using positive and negative emotional words. Am J Psychiatr 2003; 160(11): 1938-45.

[96] Gutchess AH, Kensinger EA, Schacter DL. Aging, self-referencing, and medial prefrontal cortex. Soc Neurosci 2007; 2(2): 117-33.

[97] Han S, Mao L, Gu X, Zhu Y, Ge J, Ma Y. Neural consequences of religious belief on self-referential processing. Soc Neurosci 2008; 3(1): 1-15.

[98] Heatherton TF, Wyland CL, Macrae CN, Demos KE, Denny BT, Kelley WM. Medial prefrontal activity differentiates self from close others. Soc Cogn Affect Neurosci 2006; 1(1): 18-25.

[99] Jenkins AC, Mitchell JP. Medial prefrontal cortex subserves diverse forms of self-reflection. Soc Neurosci 2011; 6(3): 211-8.

[100] Kelley WM, Macrae CN, Wyland CL, Caglar S, Inati S, Heatherton TF. Finding the self? An event-related fMRI study. J Cogn Neurosci 2002; 14(5): 785-94.

[101] Kjaer TW, Nowak M, Lou HC. Reflective self-awareness and conscious states: pet evidence for a common midline parietofrontal core. Neuroimage 2002; 17(2): 1080-6.

[102] Lemogne C, le Bastard G, Mayberg H, et al. In search of the depressive self: extended medial prefrontal network during selfreferential processing in major depression. Soc Cogn Affect Neurosci 2009; 4(3): 305-12.

[103] Lemogne C, Mayberg H, Bergouignan L, et al. Self-referential processing and the prefrontal cortex over the course of depression: a pilot study. J Affect Disord 2010; 124(1-2): 196-201.

[104] Lieberman MD, Jarcho JM, Satpute AB. Evidence-based and intuition-based self-knowledge: an FMRI study. J Pers Soc Psychol 2004; 87(4): 421-35.

[105] Lou HC, Luber B, Crupain M, et al. Parietal cortex and representation of the mental Self. Proc Natl Acad Sci USA 2004; 101(17): $6827-32$.

[106] Macrae CN, Moran JM, Heatherton TF, Banfield JF, Kelley WM. Medial prefrontal activity predicts memory for self. Cereb Cortex 2004; 14(6): 647-54.

[107] Modinos G, Ormel J, Aleman A. Activation of anterior insula during self-reflection. PLoS One 2009; 4(2): e4618.

[108] Moran JM, Heatherton TF, Kelley WM. Modulation of cortical midline structures by implicit and explicit self-relevance evaluation. Soc Neurosci 2009; 4(3): 197-211.

[109] Moran JM, Macrae CN, Heatherton TF, Wyland CL, Kelley WM. Neuroanatomical evidence for distinct cognitive and affective components of self. J Cogn Neurosci 2006; 18(9): 1586-94.

[110] Ng SH, Han S, Mao L, Lai JCL. Dynamic bicultural brains: fMRI study of their flexible neural representation of self and significant others in response to culture primes. Asian J Soc Psychol 2010; 13(2): 83-91.

[111] Ochsner KN, Beer JS, Robertson ER, et al. The neural correlates of direct and reflected self-knowledge. Neuroimage 2005; 28(4): 797814.

[112] Pfeifer JH, Lieberman MD, Dapretto M. "I know you are but what am I?!": neural bases of self- and social knowledge retrieval in children and adults. J Cogn Neurosci 2007; 19(8): 1323-37.

[113] Rameson LT, Satpute AB, Lieberman MD. The neural correlates of implicit and explicit self-relevant processing. Neuroimage 2010; 50(2): 701-8.

[114] Ries ML, Jabbar BM, Schmitz TW, et al. Anosognosia in mild cognitive impairment: relationship to activation of cortical midline structures involved in self-appraisal. J Int Neuropsychol Soc 2007; 13(3): 450-61.

[115] Schmitz TW, Kawahara-Baccus TN, Johnson SC. Metacognitive evaluation, self-relevance, and the right prefrontal cortex. Neuroimage 2004; 22(2): 941-7.

[116] Schmitz TW, Rowley HA, Kawahara TN, Johnson SC. Neural correlates of self-evaluative accuracy after traumatic brain injury. Neuropsychologia 2006; 44(5): 762-73.

[117] Vanderwal T, Hunyadi E, Grupe DW, Connors CM, Schultz RT. Self, mother and abstract other: an fMRI study of reflective social processing. Neuroimage 2008; 41(4): 1437-46. 
[118] Wu Y, Wang C, He X, Mao L, Zhang L. Religious beliefs influence neural substrates of self-reflection in Tibetans. Soc Cogn Affect Neurosci 2010; 5(2-3): 324-31.

[119] Yaoi K, Osaka N, Osaka M. Is the self special in the dorsomedial prefrontal cortex? An fMRI study. Soc Neurosci 2009; 4(5): 45563

[120] Yoshimura S, Ueda K, Suzuki S, Onoda K, Okamoto Y, Yamawaki S. Self-referential processing of negative stimuli within the ventral anterior cingulate gyrus and right amygdala. Brain Cogn 2009; 69(1): 218-25

[121] Zhang L, Zhou T, Zhang J, Liu Z, Fan J, Zhu Y. In search of the Chinese self: an fMRI study. Sci China C Life Sci 2006; 49(1): 8996.

[122] Zhu Y, Zhang L, Fan J, Han S. Neural basis of cultural influence on self-representation. Neuroimage 2007; 34(3): 1310-6.

[123] Libby LK, Eibach RP. How the self affects and reflects the content and subjective experience of autobiographical memory. Sedikides C, Spencer S, Eds. New York: Psychology Press 2007; pp. 77-91.

[124] Markowitsch HJ, Staniloiu A. Memory, autonoetic consciousness, and the self. Conscious Cogn 2011; 20(1): 16-39.

[125] Wheeler MA, Stuss DT, Tulving E. Toward a theory of episodic memory: the frontal lobes and autonoetic consciousness. Psychol Bull 1997; 121(3): 331-54.

[126] Spreng RN, Mar RA, Kim ASN. The common neural basis of autobiographical memory, prospection, navigation, theory of mind, and the default mode: a quantitative meta-analysis. J Cogn Neurosci 2009; 21(3): 489-510.

[127] Daselaar SM, Rice HJ, Greenberg DL, Cabeza R, LaBar KS, Rubin DC. The spatiotemporal dynamics of autobiographical memory: neural correlates of recall, emotional intensity, and reliving. Cereb Cortex 2008; 18(1): 217-29.

[128] Conway MA. Memory and the self. J Mem Lang 2005; 53(4): 594628 .

[129] Larsen SF, Schrauf RW, Fromholt P, Rubin DC. Inner speech and bilingual autobiographical memory: a Polish-Danish cross-cultural study. Memory 2002; 10(1): 45-54.

[130] Schrauf RW. Bilingual inner speech as the medium of crossmodular retrieval in autobiographical memory. Behav Brain Sci 25(6): 698-9.

[131] Nolde SF, Johnson MK, D'Esposito M. Left prefrontal activation during episodic remembering: an event-related fMRI study. Neuroreport 1998; 9(15): 3509-14.

[132] Botzung A, Denkova E, Ciuciu P, Scheiber C, Manning L. The neural bases of the constructive nature of autobiographical memories studied with a self-paced fMRI design. Memory 2008; 16(4): 351-63.

[133] Botzung A, Denkova E, Manning L. Experiencing past and future personal events: functional neuroimaging evidence on the neural bases of mental time travel. Brain Cogn 2008; 66(2): 202-12.

[134] Burianova H, McIntosh AR, Grady CL. A common functional brain network for autobiographical, episodic, and semantic memory retrieval. Neuroimage 2010; 49(1): 865-74.

[135] Cabeza R, Daselaar SM, Dolcos F, Prince SE, Budde M, Nyberg L. Task-independent and task-specific age effects on brain activity during working memory, visual attention and episodic retrieval. Cereb Cortex 2004; 14(4): 364-75.

[136] Campitelli G, Parker A, Head K, Gobet F. Left lateralization in autobiographical memory: An fMRI study using the expert archival paradigm. Int J Neurosci 2008; 118(2): 191-209.

[137] Conway MA, Turk DJ, Miller SL, et al. A positron emission tomography (PET) study of autobiographical memory retrieval. Memory 1999; 7(5-6): 679-702.

[138] Fink GR, Markowitsch HJ, Reinkemeier M, Bruckbauer T, Kessler J, Heiss WD. Cerebral representation of one's own past: neural networks involved in autobiographical memory. J Neurosci 1996; 16(13): 4275-82.

[139] Harrison BJ, Pujol J, Ortiz H, Fornito A, Pantelis C, Yücel M. Modulation of brain resting-state networks by sad mood induction. PLoS One 2008; 3(3): e1794.

[140] Kelly S, Lloyd D, Nurmikko T, Roberts N. Retrieving autobiographical memories of painful events activates the anterior cingulate cortex and inferior frontal gyrus. J Pain 2007; 8(4): $307-$ 14.

[141] Kross E, Davidson M, Weber J, Ochsner K. Coping with emotions past: the neural bases of regulating affect associated with negative autobiographical memories. Biol Psychiatry 2009; 65(5): 361-6.
[142] Levine B, Turner GR, Tisserand D, Hevenor SJ, Graham SJ, McIntosh AR. The functional neuroanatomy of episodic and semantic autobiographical remembering: a prospective functional MRI study. J Cogn Neurosci 2004; 16(9): 1633-46.

[143] Loughead JW, Luborsky L, Weingarten CP, et al. Brain activation during autobiographical relationship episode narratives: a core conflictual relationship theme approach. Psychother Res 2010; 20(3): 321-36.

[144] Maguire EA, Mummery CJ. Differential modulation of a common memory retrieval network revealed by positron emission tomography. Hippocampus 1999; 9(1): 54-61.

[145] Maguire EA, Frith CD. Aging affects the engagement of the hippocampus during autobiographical memory retrieval. Brain 2003; 126(Pt 7): 1511-23.

[146] Oddo S, Lux S, Weiss PH, et al. Specific role of medial prefrontal cortex in retrieving recent autobiographical memories: an fMRI study of young female subjects. Cortex 2010; 46(1): 29-39.

[147] Piefke M, Weiss PH, Zilles K, Markowitsch HJ, Fink GR. Differential remoteness and emotional tone modulate the neural correlates of autobiographical memory. Brain 2003; 126(Pt 3): 65068.

[148] Piolino P, Chételat G, Matuszewski V, et al. In search of autobiographical memories: A PET study in the frontal variant of frontotemporal dementia. Neuropsychologia 2007; 45(12): 273043.

[149] Rabin JS, Gilboa A, Stuss DT, Mar RA, Rosenbaum RS. Common and unique neural correlates of autobiographical memory and theory of mind. J Cogn Neurosci 2010; 22(6): 1095-111.

[150] St Jacques P, Rubin DC, LaBar KS, Cabeza R. The short and long of it: neural correlates of temporal-order memory for autobiographical events. J Cogn Neurosci 2008; 20(7): 1327-41.

[151] Spreng RN, Grady CL. Patterns of brain activity supporting autobiographical memory, prospection, and theory of mind, and their relationship to the default mode network. J Cogn Neurosci 2010; 22(6): 1112-23.

[152] Summerfield JJ, Hassabis D, Maguire EA. Cortical midline involvement in autobiographical memory. Neuroimage 2009; 44(3): 1188-200.

[153] Svoboda E, Levine B. The effects of rehearsal on the functional neuroanatomy of episodic autobiographical and semantic remembering: a functional magnetic resonance imaging study. J Neurosci 2009; 29(10): 3073-82.

[154] Colombetti G. What language does to feelings. J Conscious Stud 2009; 16(9): 4-26.

[155] Ochsner KN, Gross JJ. Cognitive emotion regulation: Insights from social cognitive and affective neuroscience. Curr Dir Psychol Sci 2008; 17(2): 153-8.

[156] Critchley HD, Wiens S, Rotshtein P, Ohman A, Dolan RJ. Neural systems supporting interoceptive awareness. Nat Neurosci 2004; 7(2): 189-95.

[157] Goldberg II, Harel M, Malach R. When the brain loses its self: prefrontal inactivation during sensorimotor processing. Neuron 2006; 50(2): 329-39.

[158] Gusnard DA, Akbudak E, Shulman GL, Raichle ME. Medial prefrontal cortex and self-referential mental activity: relation to a default mode of brain function. Proc Natl Acad Sci USA 2001; 98(7): 4259-64.

[159] Herwig U, Kaffenberger T, Jäncke L, Brühl AB. Self-related awareness and emotion regulation. Neuroimage 2010; 50(2): 734 41.

[160] Jackson PL, Brunet E, Meltzoff AN, Decety J. Empathy examined through the neural mechanisms involved in imagining how I feel versus how you feel pain. Neuropsychologia 2006; 44(5): 752-61.

[161] Lane RD, Fink GR, Chau PM-L, Dolan RJ. Neural activation during selective attention to subjective emotional responses. Neuroreport 1997; 8(18): 3969-72.

[162] Ochsner KN, Knierim K, Ludlow DH, et al. Reflecting upon feelings: an fMRI study of neural systems supporting the attribution of emotion to self and other. J Cogn Neurosci 2004; 16(10): 1746-72.

[163] Phan KL, Taylor SF, Welsh RC, Ho S-H, Britton JC, Liberzon I Neural correlates of individual ratings of emotional salience: a trial-related fMRI study. Neuroimage 2004; 21(2): 768-80.

[164] Schneider F, Bermpohl F, Heinzel A, et al. The resting brain and our self: self-relatedness modulates resting state neural activity in cortical midline structures. Neuroscience 2008; 157(1): 120-31. 
[165] Sheline YI, Barch DM, Price JL, et al. The default mode network and self-referential processes in depression. Proc Natl Acad Sci USA 2009; 106(6): 1942-7.

[166] Silani G, Bird G, Brindley R, Singer T, Frith C, Frith U. Levels of emotional awareness and autism: an fMRI study. Soc Neurosci 2008; 3(2): 97-112.

[167] Takahashi H, Yahata N, Koeda M, Matsuda T, Asai K, Okubo Y. Brain activation associated with evaluative processes of guilt and embarrassment: an fMRI study. Neuroimage 2004; 23(3): 967-74.

[168] Takahashi H, Matsuura M, Koeda M, et al. Brain activations during judgments of positive self-conscious emotion and positive basic emotion: pride and joy. Cereb Cortex 2008; 18(4): 898-903.

[169] Taylor SF, Phan KL, Decker LR, Liberzon I. Subjective rating of emotionally salient stimuli modulates neural activity. Neuroimage 2003; 18(3): 650-9.

[170] Blakemore S-J, den Ouden H, Choudhury S, Frith C. Adolescent development of the neural circuitry for thinking about intentions. Soc Cogn Affect Neurosci 2007; 2(2): 130 -39.

[171] Quoidbach J, Hansenne M, Mottet C. Personality and mental time travel: a differential approach to autonoetic consciousness. Conscious Cogn 2008; 17(4): 1082-92.

[172] Szpunar KK. Episodic future thought: An emerging concept. Perspect Psychol Sci 2010; 5(2): 142-62.

[173] D'Argembeau A, Renaud O, Van Der Linden M. Frequency, characteristics and functions of future-oriented thoughts in daily life. Appl Cogn Psychol 2011; 25(1): 96-103.

[174] Suddendorf T, Addis DR, Corballis MC. Mental time travel and the shaping of the human mind. Philos Trans R Soc Lond B Biol Sci 2009; 364(1521): 1317-24.

[175] Addis DR, Wong AT, Schacter DL. Remembering the past and imagining the future: common and distinct neural substrates during event construction and elaboration. Neuropsychologia 2007; 45(7): 1363-77.

[176] Arzy S, Collette S, Ionta S, Fornari E, Blanke O. Subjective mental time: the functional architecture of projecting the self to past and future. Eur J Neurosci 2009; 30(10): 2009-17.

[177] Binder JR, Frost JA, Hammeke TA, Bellgowan PS, Rao SM, Cox RW. Conceptual processing during the conscious resting state. A functional MRI study. J Cogn Neurosci 1999; 11(1): 80-95.

[178] Christoff K, Ream JM, Gabrieli JDE. Neural basis of spontaneous thought processes. Cortex 2004; 40(4-5): 623-30.

[179] D'Argembeau A, Xue G, Lu Z-L, Van der Linden M, Bechara A. Neural correlates of envisioning emotional events in the near and far future. Neuroimage 2008; 40(1): 398-407.

[180] Fransson P. Spontaneous low-frequency BOLD signal fluctuations: an fMRI investigation of the resting-state default mode of brain function hypothesis. Hum Brain Mapp 2005; 26(1): 15-29.

[181] Johnson SC, Schmitz TW, Kawahara-Baccus TN, et al. The Cerebral Response during Subjective Choice with and without Selfreference. J Cogn Neurosci 2005; 17(12): 1897-906.
[182] Johnson MK, Raye CL, Mitchell KJ, Touryan SR, Greene EJ, Nolen-Hoeksema S. Dissociating medial frontal and posterior cingulate activity during self-reflection. Soc Cogn Affect Neurosci 2006; 1(1): 56 -64.

[183] Longe O, Maratos FA, Gilbert $\mathrm{P}$, et al. Having a word with yourself: neural correlates of self-criticism and self-reassurance. Neuroimage 2010; 49(2): 1849-56.

[184] Mazoyer B, Zago L, Mellet E, et al. Cortical networks for working memory and executive functions sustain the conscious resting state in man. Brain Res Bull 2001; 54(3): 287-98.

[185] Pan X, Hu Y, Li L, Li J. Evaluative-feedback stimuli selectively activate the self-related brain area: an fMRI study. Neurosci Lett 2009; 465(1): 90-4.

[186] Paulus MP, Frank LR. Ventromedial prefrontal cortex activation is critical for preference judgments. Neuroreport 2003; 14(10): 13115.

[187] Pfeifer JH, Masten CL, Borofsky LA, Dapretto M, Fuligni AJ, Lieberman MD. Neural correlates of direct and reflected selfappraisals in adolescents and adults: when social perspective-taking informs self-perception. Child Dev 2009; 80(4): 1016-38.

[188] Piech RM, Lewis J, Parkinson CH, et al. Neural correlates of appetite and hunger-related evaluative judgments. PLoS One 2009; 4(8): e6581.

[189] Seger CA, Stone M, Keenan JP. Cortical Activations during judgments about the self and an other person. Neuropsychologia 2004; 42(9): 1168-77.

[190] Szpunar KK, Watson JM, McDermott KB. Neural substrates of envisioning the future. Proc Natl Acad Sci USA 2007; 104(2): 6427.

[191] Weiler JA, Suchan B, Daum I. When the future becomes the past: Differences in brain activation patterns for episodic memory and episodic future thinking. Behav Brain Res 2010; 212(2): 196-203.

[192] Zysset S, Huber O, Ferstl E, von Cramon DY. The anterior frontomedian cortex and evaluative judgment: an fMRI study. Neuroimage 2002; 15(4): 983-91.

[193] Morin A. What are animals conscious of? In: Smith J, Mitchell RW, Schneider MS, Eds. Minds of Animals. (In Press).

[194] Edelman GM, Gally JA, Baars BJ. Biology of consciousness. Front Psychol 2011; 25: 2.

[195] Garfield JL, Peterson CC, Perry T. Social cognition, language acquisition and the development of the theory of mind. Mind Lang 2001; 16(5): 494-541.

[196] Femyhough C, Meins E. Private speech and theory of mind: Evidence for developing interfunctional relations. In: Winsler A, Fernyhough C, Montero I, Eds. Private speech, executive functioning, and the development of verbal self-regulation. New York, NY US: Cambridge University Press 2009; pp. 95-104.

[197] Carrington SJ, Bailey AJ. Are there theory of mind regions in the brain? A review of the neuroimaging literature. Hum Brain Mapp 2009; 30(8): 2313-35.

(C) Morin and Hamper; Licensee Bentham Open.

This is an open access article licensed under the terms of the Creative Commons Attribution Non-Commercial License (http://creativecommons.org/licenses/bync/3.0/), which permits unrestricted, non-commercial use, distribution and reproduction in any medium, provided the work is properly cited. 